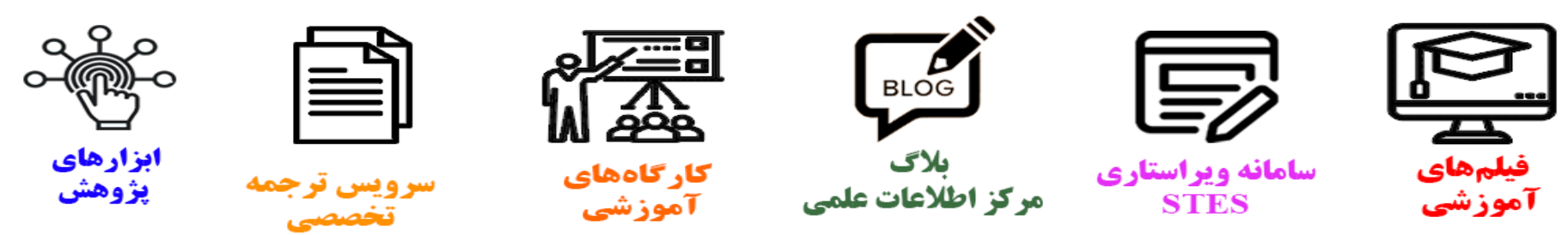

\title{
(c)
}

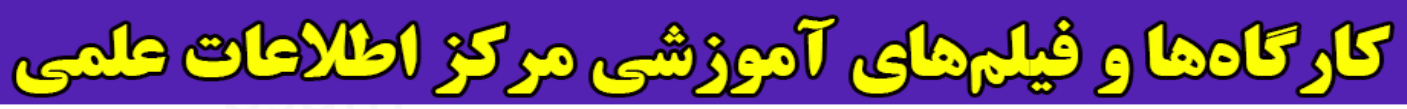
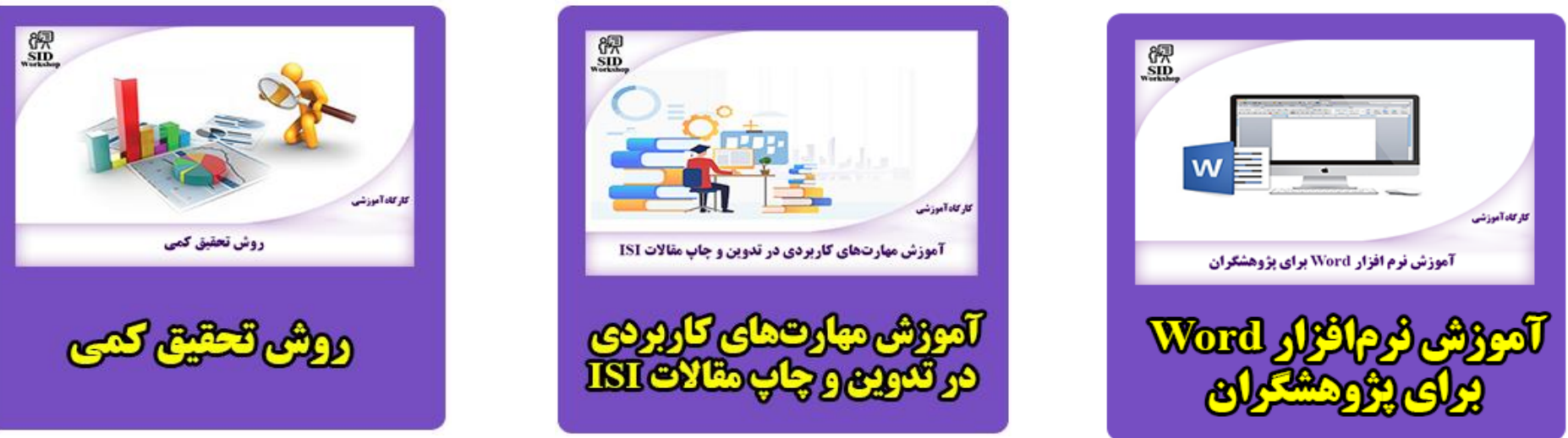


\title{
RESEARCH NOTE
}

\section{INVESTIGATION ON MICROSTRIP PATCH FRACTAL ANTENNA}

\author{
E. Richa Garg* \\ Department of ECE, J.C.D.M. College of Engineering, Sirsa, India \\ richa.jan11@gmail.com \\ *Corresponding Author
}

(Received: December 12, 2011 - Accepted in Revised Form: January 19, 2012)

doi: 10.5829/idosi.ije.2012.25.01c.05

\begin{abstract}
A new design of Microsrtip patch fractal antenna for $2.5 \mathrm{GHz}$ is proposed which possess an excellent size reduction possibility with good radiation performance for wireless applications like Wireless Local Area Network (WLAN). The design and simulation results of microstrip patch fractal antenna using Ansoft HFSS is presented which has $\mathrm{S}_{11}<-10 \mathrm{~dB}(\mathrm{VSWR}<2)$. The antenna is designed based on the transmission line model with the input impedance of $50 \mathrm{ohm}$. The fractal geometry for the conventional antenna is generated up to second iteration. The results show that size reduction of $51.9 \%$ can be achieved as compared to conventional patch antenna.
\end{abstract}

Keywords Fractal Antenna; Miniaturization of Antenna; Microstrip Fractal Antenna; Wireless Local Area Network (WLAN)

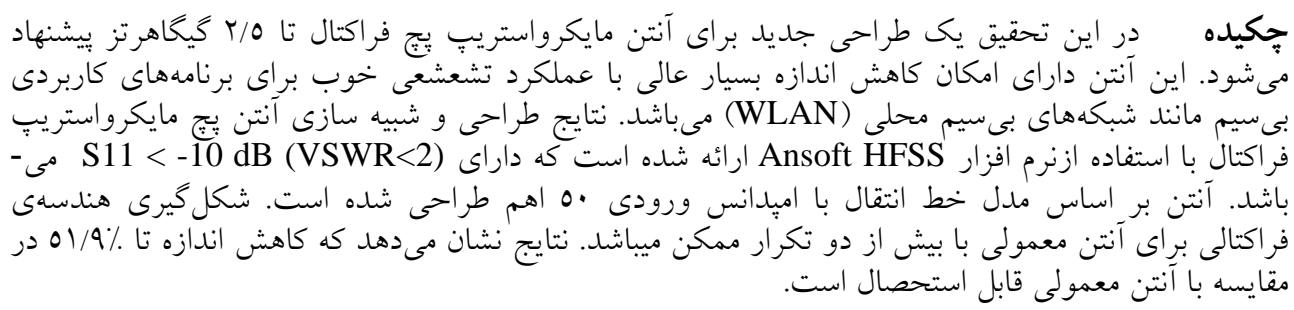

\section{INTRODUCTION}

Nowadays, with the advancement of wireless communication systems and their miniaturization, antenna design has become more significant. The main reason of Microstrip patch antenna (MPA) to attract wide interest is its inherent characteristics such as light weight, low profile, low cost, mechanically robust, and simple to manufacture, easy to be integrated with MIC/MMIC( microwave integrated circuit/ monolithic MIC) and others RF devices. The microstrip antenna has been investigated by several researchers in the literature [1-3]. Miniaturization of microstrip patch antennas is a current topic of interest. In literature, there are several methods to reduce the size of microstip patch antennas such as shorting pins and planes, using fractals, introducing of U slots, using of high permittivity materials $[4,5]$.

The topic of interest here is fractals. Fractal is a recursively generated structure having a selfsimilar shape, which means that some of the parts have the same shape as the whole object but at a different scale. The initial shape considered is zeroth order fractal and the shapes derived later on after cutting the desired parts are known as corresponding order fractals. They are space filling contours, meaning electrically large features can be efficiently packed into small areas [6]. Since the electrical lengths play such an important role in antenna design, this efficient packing can be used as an antenna miniaturization technique [7]. 


\section{FINAL ANTENNA GEOMETRY AND SIMULATION RESULTS}

Antenna Geometry

The initiator for the proposed Fractal Antenna is simple conventional Microstrip Patch designed on FR4 substrate with $\varepsilon_{\mathrm{r}}=4.4$ as shown in Fig. 1

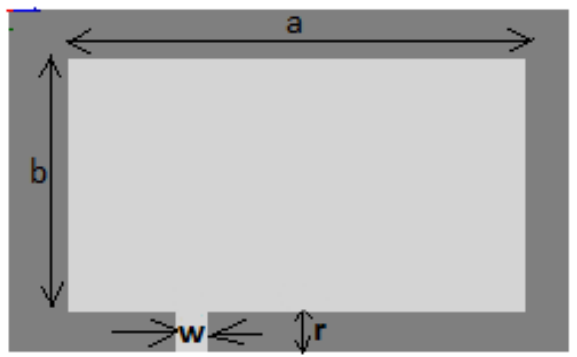

$a=38 \mathrm{~mm}$

$\mathrm{b}=27 \mathrm{~mm}$

$\mathrm{w}=2.5 \mathrm{~mm}$

$\mathrm{r}=4 \mathrm{~mm}$

Figure 1. The Microstrip patch antenna (Initiator)

From the simulations and measurements, the optimized dimensions for the initiator (zeroth order fractal) are given in Table 1.

TABLE1. The Antenna Parameters

\begin{tabular}{ll|l|l|l|}
\hline & Ground & Substrate & Patch & Feed \\
\hline Length(mm) & 36 & 36 & 27 & 4 \\
Width (mm) & 47 & 47 & 38 & 2.5 \\
Height (mm) & 0.02 & 1.5 & 0.02 & 0.02 \\
Material & PEC & $\begin{array}{l}\text { FR4 } \\
\text { Epoxy }\end{array}$ & PEC & PEC \\
\hline
\end{tabular}

In the design of antenna structure, we use a rectangular structure which acts as a port to provide the feed to the antenna. It should be noted that the designed structure of a microstrip antenna was fed by a microstrip feeding technique. The microstrip antenna substrate is enclosed in a radiation box which is larger in dimension $(\mathrm{l} \mathrm{x} \mathrm{b} \mathrm{x}$ $\mathrm{h})$. The antenna structures are then assigned with the analysis set-up which encloses solution frequency, start and stop frequency of simulations, step size, Maximum number of passes and etc. The results for initiator are shown in Figs. 2-4 for return losses, radiation pattern and polar plot.

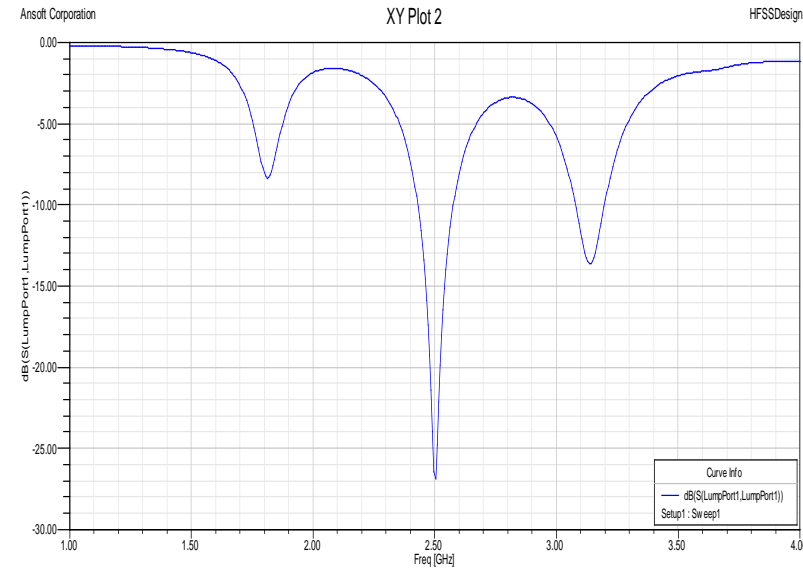

Figure 2. The return loss $\left(\mathrm{S}_{11}, \mathrm{~dB}\right)$ versus frequency $(\mathrm{GHz})$ plot for initiator

Bandwidth calculations

Bandwidth $\%=100 *\left(f_{H}-f_{L}\right) / f_{r}$; where, $f_{H}$ is the higher frequency value, $f_{L}$ is the lower frequency value crossing $-10 \mathrm{db}$ and $\mathrm{f}_{\mathrm{r}}$ is the resonant frequency. Here, in this case, $\mathrm{f}_{\mathrm{H}}=2.43, \mathrm{f}_{\mathrm{L}}=2.5718$, fr $=2.5$; bandwidth \% $=5.6$.

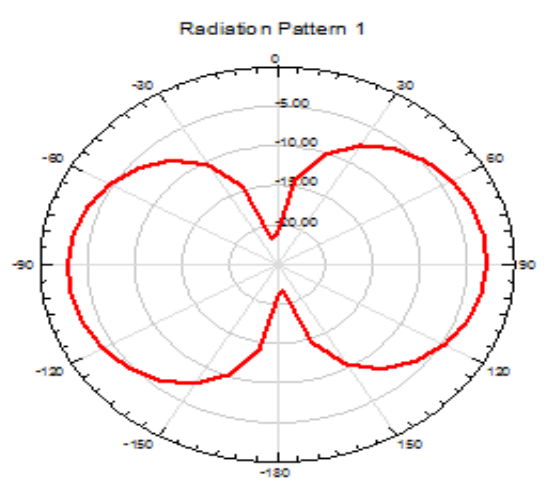

For E plane theta=0degree

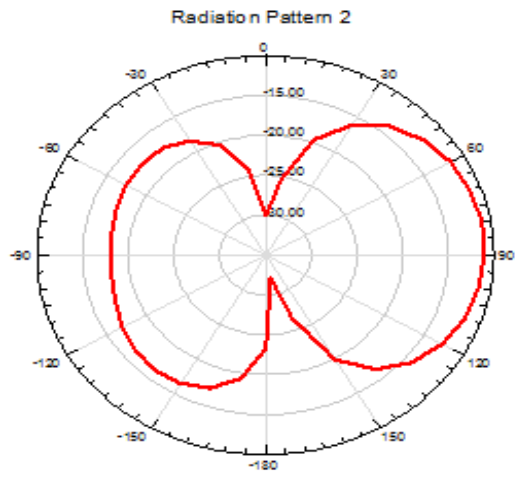

For $\mathrm{H}$ plane theta=90degree

Figure 3. Radiation Pattern for zero Order Fractal 


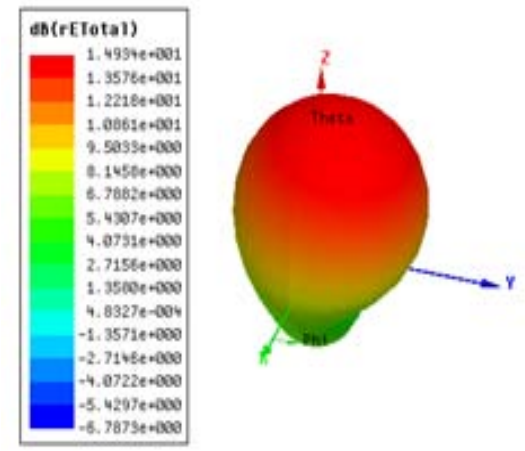

Figure 4. The illustration of the polar plot of Zero Order Fractal

\subsection{Design for First Order Fractal Microstrip} Antenna A rectangular box of (10x16x.02 mm) is cut from the zeroth order antenna's patch (36x47x.02 mm) as shown in Fig. 5 resulting in first order fractal microstrip patch antenna. The area would be reduced in first order fractal when compared to conventional patch. The results for first order fractal are shown in Figs. 6 - 8.

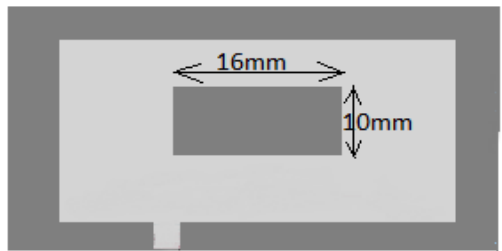

Figure 5. The First Order Fractal Microstrip antenna

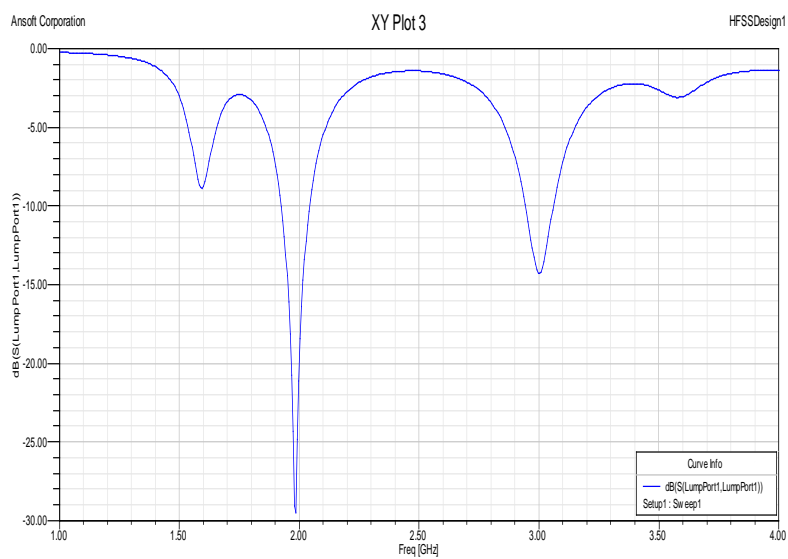

Figure 6. The return loss $\left(\mathrm{S}_{11}, \mathrm{~dB}\right)$ versus frequency (GHz) plot for First Order Fractal

It is clear from the Fig. 6 that the frequency at which resonant peak occurs is shifted to the left hand side of frequency of initiator.
Bandwidth calculations:

It is clear from the Fig. 6, that in this case

$\mathrm{f}_{\mathrm{H}}=1.9224, \mathrm{f}_{\mathrm{L}}=2.0431, \mathrm{f}_{\mathrm{r}}=1.9224$;

Bandwidth $\%=100 *\left(\mathrm{f}_{\mathrm{H}}-\mathrm{f}_{\mathrm{L}}\right) / \mathrm{f}_{\mathrm{r}} ; \mathrm{BW} \%=6$

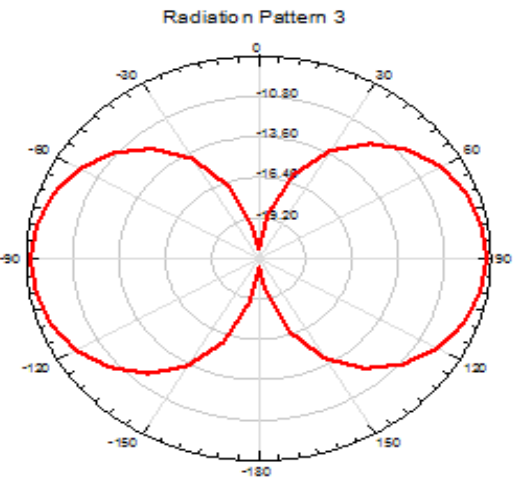

For E-plane theta=0degree

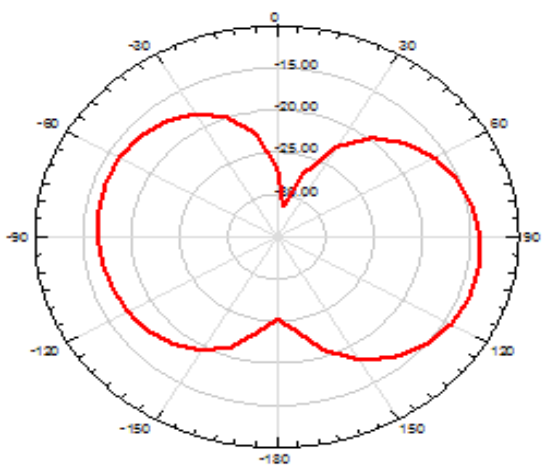

For $\mathrm{H}$ plane theta=90degree

Figure 7. Radiation Pattern for First Order Fractal
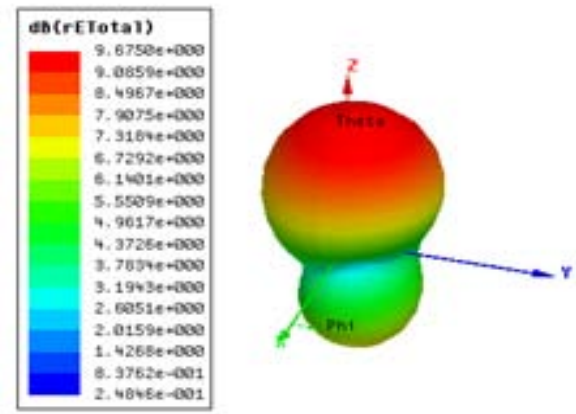

Figure 8. The illustration of the polar plot of First Order Fractal

\subsection{Design for Second Order Fractal Microstrip}

Antenna Eight rectangular boxes of size $(4 \times 4 \times .02 \mathrm{~mm})$ are cut from the first order fractal 
antenna (shown in Fig. 8) to reduce more area of patch from specified locations so as to achieve good performance. The experiment results are shown in Figs. 9-14.

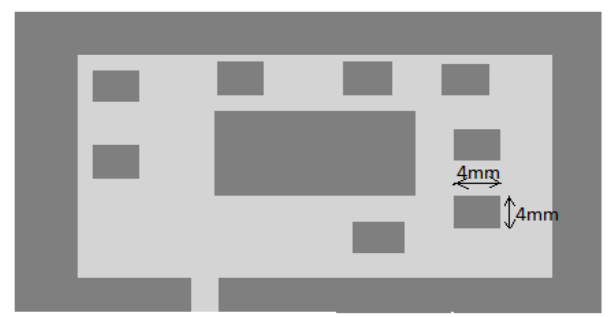

Figure 9. The Second Order Fractal Microstrip antenna

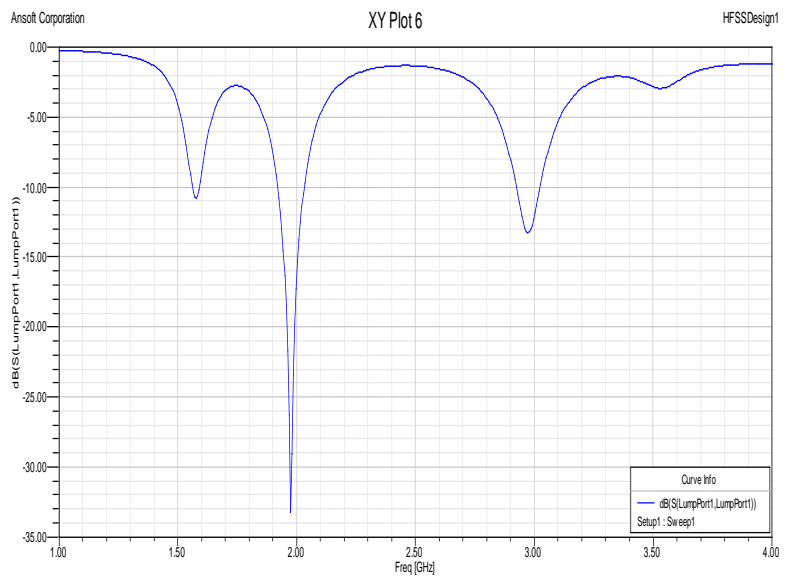

Figure 10. The return loss $\left(\mathrm{S}_{11}, \mathrm{~dB}\right)$ versus frequency $(\mathrm{GHz})$ plot for Second Order Fractal

It is also observed here that resonant frequency shifts to lower side of frequency on $\mathrm{x}$-axis.

Bandwidth calculations

$\mathrm{f}_{\mathrm{H}}=1.9198, \mathrm{f}_{\mathrm{L}}=2.0302, \mathrm{f}_{\mathrm{r}}=1.9739$;

Bandwidth \% $=5.59$

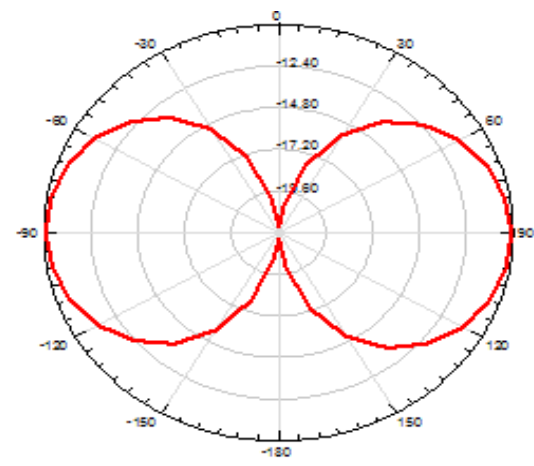

For E plane theta=0degree

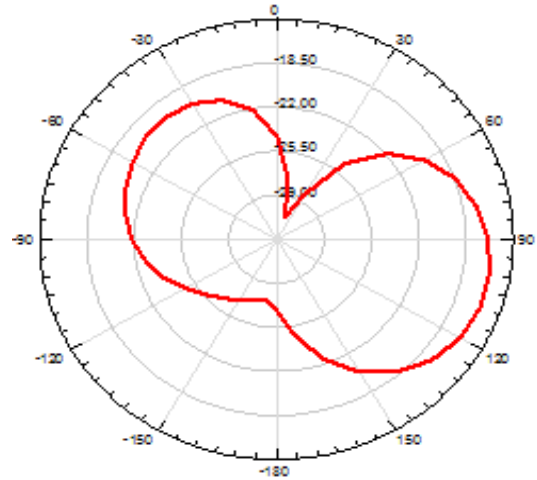

For $\mathrm{H}$ plane theta=90degree

Figure 11. Radiation Pattern for Second Order Fractal
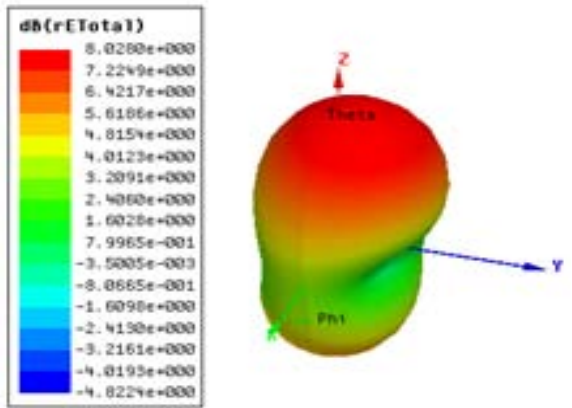

Figure 12. The illustration of the polar plot of Second Order Fractal

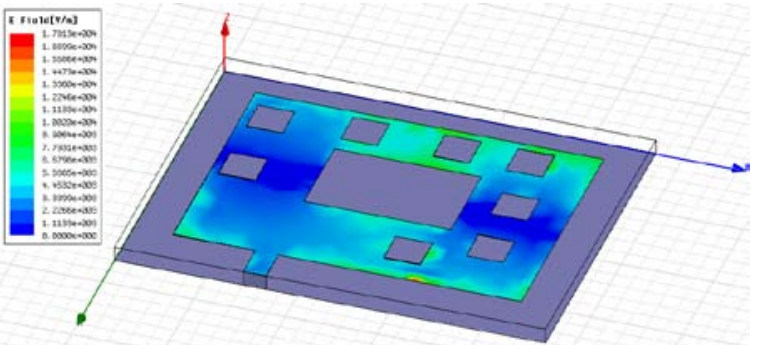

Figure 12. Current Distribution for Second Order Fractal

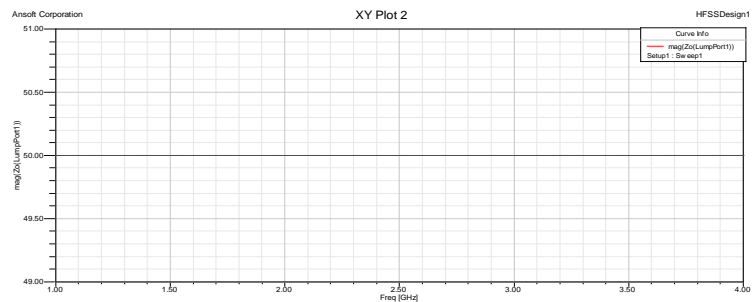

Figure 13. Port Impedance for the designed antenna

IJE Transactions C: Aspects 
The input port impedance for lumped port as shown by HFSSv11 is $50 \mathrm{ohm}$. The group delay is shown in Fig. 14 below.

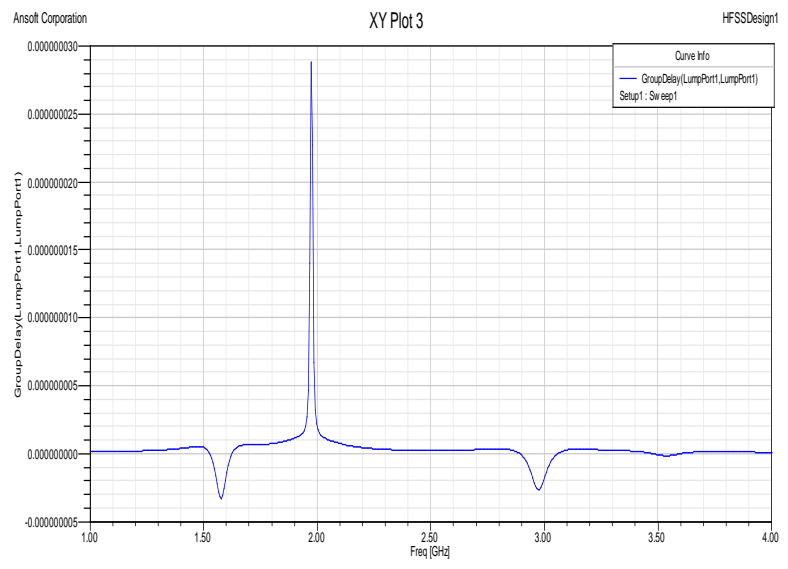

Figure 14. Group Delay for the final antenna design

\section{COMPARISONS}

According to Figs. 15-18, the return loss $\left(\mathrm{S}_{11}, \mathrm{~dB}\right)$ versus frequency (in $\mathrm{GHz}$ ) plotted for different substrate heights, Substrate materials, Feed widths and Ground Lengths are simulated and compared using Ansoft HFSS v 11.

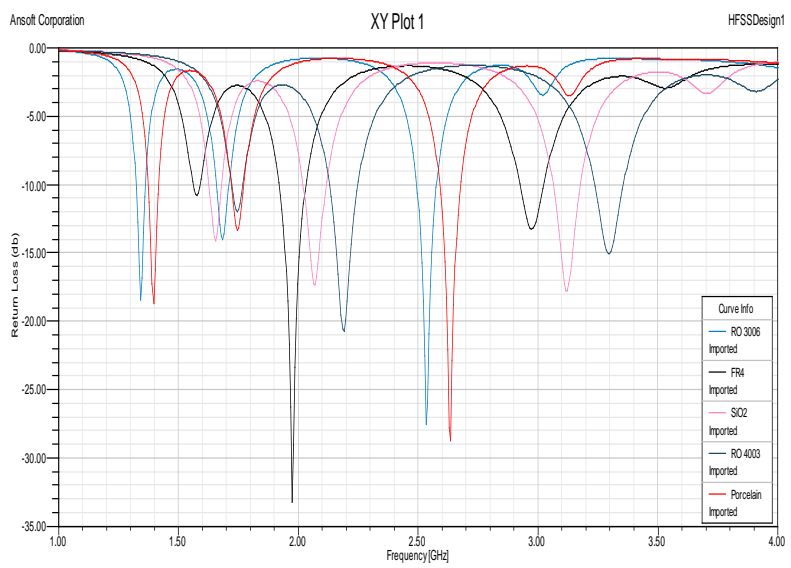

Figure 15. Effect of Substrate Material

Fig. 15 shows the effect of different substrate materials like Roger-3006, FR4-Epoxy, Silicon Dioxide, Roger 4003 and porcelain on return losses. Results show that material FR4-epoxy has best results. So, it is selected for the design.

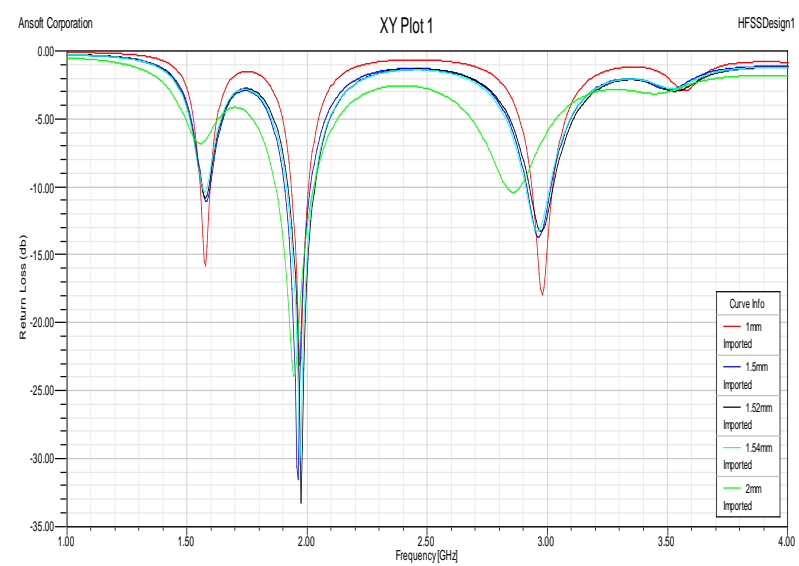

Figure 16. Effect of Substrate Height

Different substrate heights are considered like $\mathrm{h}=1 \mathrm{~mm}, 1.5 \mathrm{~mm}, 1.52 \mathrm{~mm}, 1.54 \mathrm{~mm}$ and $2 \mathrm{~mm}$. It is clear from the Fig. 16 that for Substrate height, $\mathrm{h}=1.52 \mathrm{~mm}$, the return losses are minimum. So, it is selected for final design.

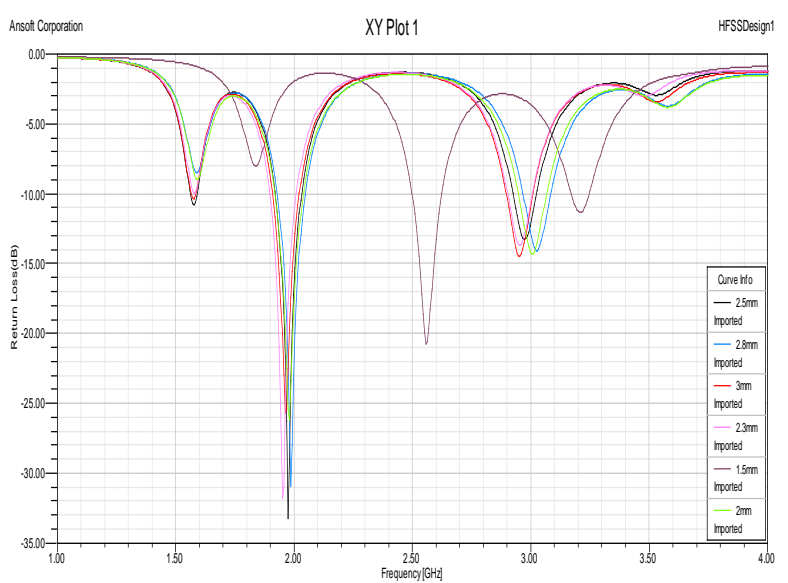

Figure 17. Effect of Feed Width

Different feed widths are considered $\mathrm{w}=1.5 \mathrm{~mm}$, $2 \mathrm{~mm}, 2.3 \mathrm{~mm}, 2.5 \mathrm{~mm}, 2.8 \mathrm{~mm}$ and $3 \mathrm{~mm}$. The feed width chosen for the final design is $1.5 \mathrm{~mm}$, as it is giving best results among others as shown above. 


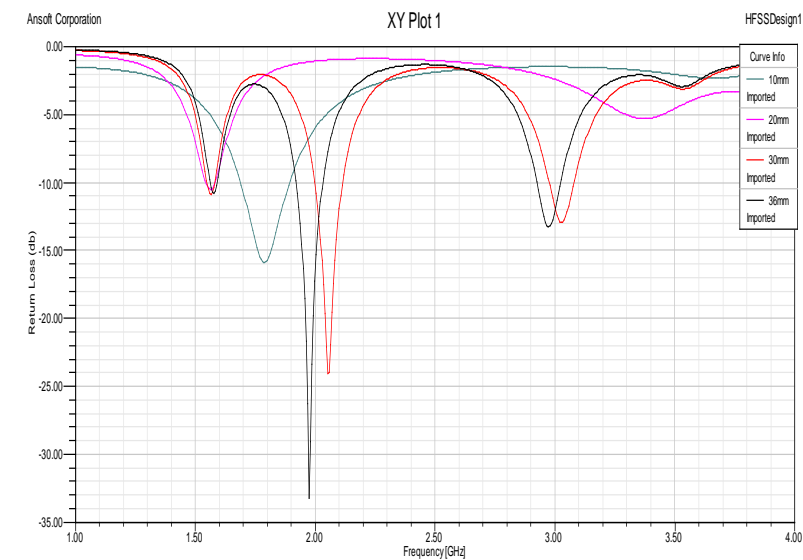

Figure 18. Effect of Ground Length

The full Ground plane considered in the design of fractal antenna as the losses are minimum for this case as shown in Fig. 18. Considering the entire above effects, fractal patch antenna is designed.

\section{CONCLUSION}

The first resonant frequency of first order fractal and second order fractal antenna are compared with the well known Microstrip patch antenna. It has been shown that two presented antennas have lower first resonant frequencies that cause a noticeable reduction in the size of the antennas. A total of $51.9 \%$ size reduction from conventional patch antenna can be achieved by the microstrip patch fractal antenna of the second iteration order, without affecting the other performances such as return loss and radiation pattern. Thus, the fractal patch antenna can be used to replace a normal rectangular patch. It included similar characteristic of radiation pattern and smaller patch size compared to that of a rectangular patch.

\section{REFERENCES}

1. Shackelford, A., Lee, K.F., Chatterjee, D., Guo, Y.X., Luk, K.M. and Chair, R., "Small-Size Wide-Bandwidth Microstrip Patch Antennas", Institute of Electric and Electronics Engineers, (2001), 86-89.

2. Chen W.L. and Wang, G.M., "Small Size Edge-fed Sierpinski carpet microstrip patch antennas", Progress in Electromagnetics Research, Vol. 3, (2008), 195-202.

3. Kumar, R., Malathi, P. and Ganesh, G., "On the Miniaturization of Printed Rectangular Microstrip Antenna for Wireless Applications", Institute of Electric and Electronics Engineers, (2007), 334-336.

4. Garg, R., "Progress in Microstrip antennas", IETE Technical Review, Vol. 18, No.2 \& 3, (2001), 85-98.

5. Shackelford, A.K., Lee, K.F., Luk, K.M., "Design of Small - Size Wide - Bandwidth Microstrip Patch Antennas" Institute of Electric and Electronics Engineers, AP -45, Magazine, No.1, (2003), 75-83.

6. Best, S.R., "The Effectiveness of Space Filling Fractal Geometry in Lowering Resonant Frequency”, Antennas and Propagation Letters, Vol. 1, (2002), 112-115.

7. Mohammed, S.S., Ramasamy, K. and Shanmuganantham, T., “A Sierpinski Fractal Based Micro strip Patch Antenna for Wireless Power Transmission System", International Journal of Computer Applications, Vol. 1, No. 13, (2010), 104108. 


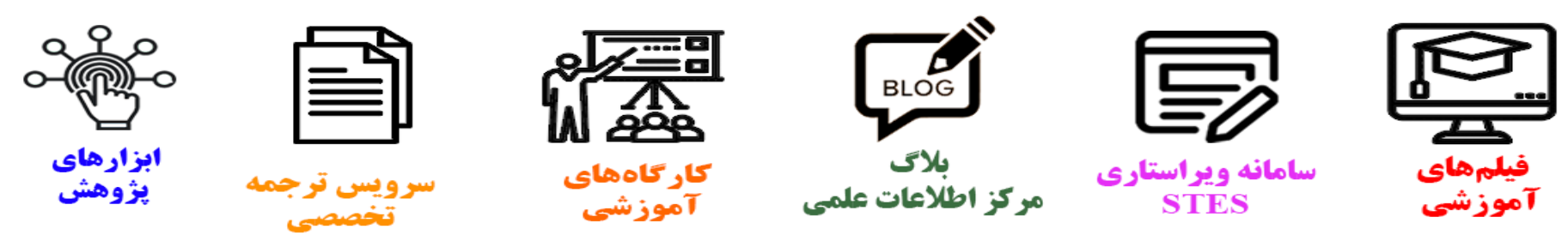

\section{(c)}

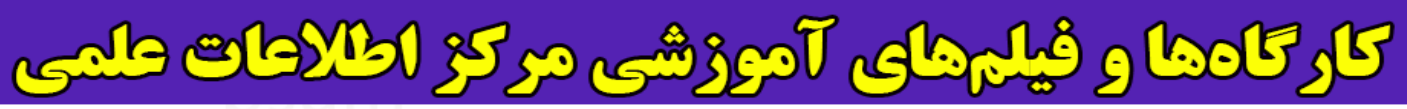
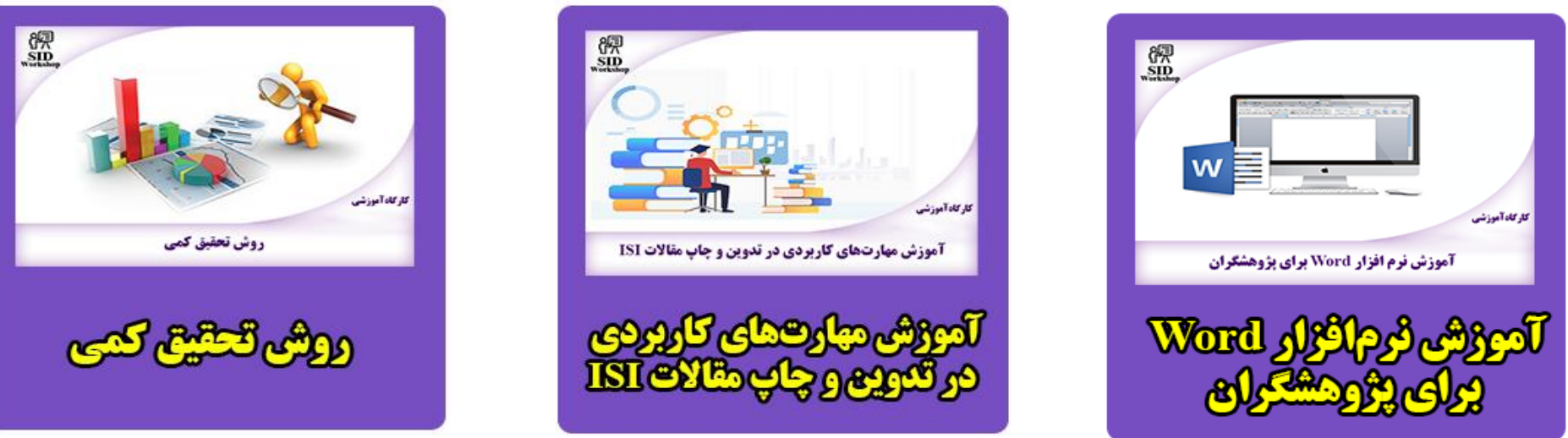